\title{
The Influence of Education and Depression on Autonomy of Women with Chronic Pelvic Pain: A Cross-sectional Study
}

\section{A influência da educação e depressão sobre a autonomia de mulheres com dor pélvica crônica: um estudo transversal}

\author{
Hermes de Freitas Barbosa ${ }^{1}$ Antonio Alberto Nogueira ${ }^{2}$ Júlio César Rosa e Silva ${ }^{2}$ \\ Omero Benedicto Poli Neto ${ }^{2}$ Francisco José Candido dos Reis ${ }^{2}$ \\ ${ }^{1}$ Department of Pathology and Legal Medicine, Ribeirao Preto School
of Medicine, University of Sao Paulo, Ribeirao Preto, Brazil
2 Department of Gynecology and Obstetrics, Ribeirao Preto School of
Medicine, University of Sao Paulo, Ribeirao Preto, Brazil \\ Address for correspondence Francisco José Candido dos Reis, PhD, \\ Departamento de Ginecologia e Obstetrícia, Ribeirao Preto School of \\ Medicine, University of Sao Paulo, Av. Bandeirantes 3900, 8o andar, \\ 14049-900 - Ribeirão Preto, Brazil (e-mail: fjcreis@fmrp.usp.br).
}

Rev Bras Ginec Obst 2016;38:47-52.

\begin{abstract}
Keywords

- autonomy

- diagnostic laparoscopy

- chronic pelvic pain

- education

- depression

\section{Resumo}

Palavras-chaves

- autonomia

- laparoscopia diagnóstica

- dor pélvica crônica

- educação

- depressão

Objective Patient autonomy has great importance for a valid informed consent in clinical practice. Our objectives were to quantify the domains of patient autonomy and to evaluate the variables that can affect patient autonomy in women with chronic pelvic pain.

Methods This study is a cross sectional survey performed in a tertiary care University Hospital. Fifty-two consecutive women scheduled for laparoscopic management of chronic pelvic were included. Three major components of autonomy (competence, information or freedom) were evaluated using a Likert scale with 24 validated affirmatives. Results Competence scores ( 0.85 vs $0.92 ; p=0.006)$ and information scores $(0.90$ vs $0.93 ; p=0.02$ ) were low for women with less than eight years of school attendance. Information scores were low in the presence of anxiety $(0.91$ vs $0.93 ; p=0.05)$ or depression ( 0.90 vs $0.93 ; p=0.01$ ).

Conclusions Our data show that systematic evaluation of patient autonomy can provide clinical relevant information in gynecology. Low educational level, anxiety and depression might reduce the patient autonomy in women with chronic pelvic pain.

Objetivo A autonomia da paciente é de grande importância para que o consentimento informado seja válido na prática clínica. Nossos objetivos foram quantificar os domínios da autonomia e avaliar variáveis que modificam a autonomia em mulheres com dor pélvica crônica.

Métodos Este é um estudo transversal realizado em um Hospital Universitário terciário. Foram incluídas consecutivamente 52 mulheres com dor pélvica crônica agendadas para videolaparoscopia. Foi utilizada uma escala Likert com 24 afirmativas validadas para quantificar os três principais componentes da autonomia (competência, informação e liberdade).
\end{abstract}

received

October 21, 2015

accepted

November 9, 2015

published online

$\mathrm{xxxx}$
DOI http://dx.doi.org/

10.1055/s-0035-1570107. ISSN 0100-7203.
Copyright $\odot 2016$ by Thieme Publicações License terms Ltda, Rio de Janeiro, Brazil

()ㅇㅇㅛ $\circledast$ 
Resultados Os escores de competência $(0,85$ vs 0,$92 ; p=0,006)$ e informação $(0,90$ vs 0,$93 ; p=0,02)$ foram menores para mulheres com ensino fundamental incompleto. Os escores de informação foram menores em mulheres com sintomas de ansiedade $(0,91$ vs 0,$93 ; p=0,05)$ ou depressão $(0,90$ vs 0,$93 ; p=0,01)$.

Conclusões Nossos dados mostram que a quantificação da autonomia pode produzir informações relevantes para a prática clínica em ginecologia. O nível educacional e a presença de ansiedade e depressão podem afetar a autonomia de mulheres com dor pélvica crônica.

\section{Introduction}

Informed consent is an integral part of medical decisionmaking for a patient accepting a specific treatment. ${ }^{1}$ For an informed consent to be valid, the patient has to be informed about potential effects and side effects of the treatment. The final decision whether to recommend or not the treatment should take in account the patient autonomy. Autonomy implies competence to consent, understanding of risks and benefits, and freedom to decide. ${ }^{2}$ Competence to consent refers to the ability to understand the information. The risks, benefits and alternatives available have to be informed in an accessible language. Finally, the patient has to feel free to decide in being submitted or not to the proposed procedure. According to the autonomy principle, all patients are entitled to decide on the issues related to their own life. ${ }^{3}$

With medical care moving toward patient centered approach, to understand the various aspects involved in autonomy has great importance for achieving optimal care in reproductive medicine. However, in clinical practice, a systematic evaluation of patient's autonomy is not done routinely. For women with chronic pelvic pain (CPP), the laparoscopic investigation can led to additional diagnostic procedures or treatment in $28.8 \%$ and discard unnecessary diagnostic procedures in $13 \%$ of cases. The rates of minor complications are around $2 \%$ and major complications $0.1 \%{ }^{4}$ Despite the benefits of laparoscopy in the management of selected patients with CPP, the informed consent is mandatory before the surgical intervention. In this proof of principle study, we systematically evaluated the autonomy in a consecutive series of women with CPP scheduled for diagnostic laparoscopy.

\section{Methods}

\section{Study Design and Participants}

Fifty-two consecutive patients with chronic pelvic pain scheduled to diagnostic laparoscopy were included in this crosssectional survey study. The Institutional Ethics Committee for Research provided ethical approval for this study registration number: 3973/2008) and all participants gave specific written consent before being interviewed for this study.

The inclusion criterion was: pain in pelvic region persistent for at least six months requiring laparoscopy for diagnosis and/or treatment. Women who had history of abdominal cancer or pelvic cancer were not included. The informed consents for laparoscopic procedures were obtained by the consultant gynecologist, and the application of the questionnaires for this study was conducted by one of the authors of this study. All patients had given consent to be submitted to laparoscopy by the time the questionnaires were applied. This manuscript was written based on STROBE Statement.

\section{Measures}

The questionnaire for autonomy characterization was based on five-level Likert scale and included 24 affirmations (-Table 1). The questionnaire was applied in Portuguese and the contents had been previously validated by six experts who evaluated whether test items assess the proposed autonomy domains. ${ }^{5}$ The affirmations were divided in three categories: information (11 affirmations), competence ( 6 affirmations) and freedom ( 7 affirmations). Each statement was followed by a visual analogue scale with the following alternatives and their corresponding values: strongly disagree (1), disagree (2), neither agree nor disagree (3), agree (4) and strongly agree (5). The statements were presented randomly, with positive and negative propositions. For negative propositions, the values were adjusted for the analysis. The scores for competence, information, and freedom were calculated by dividing the score obtained by the maximum possible value in the category.

Data on age, educational attainment, marital status and family monthly income, were obtained at the time of questionnaire application. Pain duration was recorded in months as informed by the patient. The current pain intensity was based on a $100 \mathrm{~mm}$ visual analogue scale: moderate pain $(45-74 \mathrm{~mm})$ and severe pain $(75-100$ $\mathrm{mm}) .{ }^{6}$ Anxiety and depression symptoms were evaluated using the Hospital Anxiety and Depression Scale (HADS). The HADS is a fourteen item scale that generates ordinal data. Seven of the items relate to anxiety and seven relate to depression. Each item is scored from zero to three. ${ }^{7}$ In this study we used the cut-off value of $8 / 21$ for anxiety or depression. ${ }^{8}$

\section{Statistical Analysis}

Statistical analysis was conducted using Stata 13 software (StataCorp LP, 2013, Texas, USA). A correlation matrix for 
Table 1 Questionnaire for autonomy quantification

\begin{tabular}{|c|c|c|}
\hline Category & Statement & Proposition \\
\hline \multirow[t]{11}{*}{ Information } & I have been informed about the proposed surgery. & Positive \\
\hline & I have been explained about the available non-surgical management for my pain. & Positive \\
\hline & I have been informed the advantages of the proposed surgery. & Positive \\
\hline & I have been informed the disadvantages of the proposed surgery. & Positive \\
\hline & I have been explained the reason for the surgery. & Positive \\
\hline & The explanations provided by the health team gave me confidence to make a decision. & Positive \\
\hline & I would like having received further information about the proposed surgery. & Negative \\
\hline & All my questions have been answered. & Positive \\
\hline & I have been informed about the risks of the proposed surgery. & Positive \\
\hline & $\begin{array}{l}\text { I got the information to make the decision about undergoing surgery from internet, } \\
\text { magazines, newspapers, TV shows or other sources. }\end{array}$ & Negative \\
\hline & $\begin{array}{l}\text { I got the information to make the decision about undergoing surgery from people who } \\
\text { underwent to the same surgery. }\end{array}$ & Negative \\
\hline \multirow[t]{6}{*}{ Competence } & I was able to understand the available alternatives to the proposed surgery. & Positive \\
\hline & I found difficult to understand the provided information about the surgery. & Negative \\
\hline & I found difficult to understand the medical terms used by the doctor. & Negative \\
\hline & I was able to understand the procedure to be performed. & Positive \\
\hline & I was able to understand the answers to my questions. & Positive \\
\hline & The risks of the surgery are not clear to me. & Negative \\
\hline \multirow[t]{7}{*}{ Freedom } & I feel free to talk to the health team about my doubts. & Positive \\
\hline & The health team listened to my concerns. & Positive \\
\hline & I felt difficulty to ask questions to the attending doctor. & Negative \\
\hline & I feel free to decide about my treatment. & Positive \\
\hline & I have not been asked about my preference for the type of treatment. & Negative \\
\hline & I did not like the way I was treated when asked about the treatment. & Negative \\
\hline & I made my decision based on the information provided by the health team. & Positive \\
\hline
\end{tabular}

autonomy components was calculated using the Pearson product-moment correlation coefficient. Univariate analyses were conducted using Student $t$-test.

\section{Results}

The baseline data are presented in - Table 2. Patients' age varied from 19 to 58 years with median of 33 years. Nineteen (37\%) reported moderate pain and $33(63 \%)$ severe pain according to VAS classification. Twenty-six patients (50\%) had pain duration between 6 months and 2 years and 26 (50\%) patients had pain duration longer than 2 years. Thirtythree (63\%) patients presented anxiety symptoms and 18 (35\%) presented depression symptoms. Twenty-six (50\%) women did not complete the fundamental compulsory education time (8 years). Forty-three (83\%) had family income lower than US\$ $1,000.00$ a month. Thirteen (25\%) women were single.
Autonomy scores varied from 0.60 to $1.00($ mean $=0.92)$ for competence, from 0.6 to 1.0 (mean $=0.92$ ) for information and from 0.80 to 1.00 (mean $=0.92$ ) for freedom. Competence and information scores were significantly correlated $(r=0.34, p=0.01)$. However, the freedom scores were not correlated with competence or information scores (- Table 3 ).

Associations between autonomy scores and patients characteristics are presented in the - Table 4. Two parameters were significantly associated with reduction of autonomy to consent in undergoing to laparoscopic diagnosis procedure: educational attainment and symptoms of depression. Women who did not complete the fundamental level of compulsory education had low competence score ( 0.85 vs $0.92 ; p=0.006)$ and low information score $(0.90$ vs $0.93 ; p=0.02)$. The information score was low for women with symptoms of anxiety (0.91 vs 0.93 ; $p=0.05)$ or depression had low information score $(0.90$ vs $0.93 ; p=0.02$ ). 
Table 2 Baseline data

\begin{tabular}{|l|l|l|}
\hline Variable & Median & Range \\
\hline Age & 33 & $19-58$ \\
\hline VAS* (pain intensity) & 85 & $45-100$ \\
\hline Pain duration (months) & 27 & $6-240$ \\
\hline & $\mathrm{N}$ & $\%$ \\
\hline Laparoscopic diagnosis & & \\
\hline Endometriosis & 24 & 46.1 \\
\hline Benign ovarian cyst & 6 & 11.5 \\
\hline Pelvic adhesion & 8 & 15.3 \\
\hline Normal & 14 & 26.9 \\
\hline HADS** & & \\
\hline Anxiety & 33 & 63.4 \\
\hline Depression & 18 & 34.6 \\
\hline Educational level & & \\
\hline Incomplete fundamental level & 26 & 50,0 \\
\hline Complete fundamental level & 22 & 42.3 \\
\hline College degree & 4 & 7.6 \\
\hline Family income (monthly) & & \\
\hline$\geq$ US\$ 1,000.00 & 9 & 17.3 \\
\hline$<$ US\$ 1,000.00 & 43 & 82.6 \\
\hline Marital status & 13 & \\
\hline Single & 39 & \\
\hline Married & & \\
\hline
\end{tabular}

Abbreviations: VAS, Visual Analogue Scale ${ }^{6}$; HADS, Hospital Anxiety and Depression Scale. ${ }^{7}$

Table 3 Matrix correlation among components of autonomy in women with chronic pelvic pain

\begin{tabular}{|l|l|l|l|}
\hline & Competence & Information & Freedom \\
\hline Competence & 1.0 & & \\
\hline Information & $\begin{array}{l}r=0.34 \\
(p=0.01)\end{array}$ & 1.0 & \\
\hline Freedom & $\begin{array}{l}r=0.08 \\
(p=0.56)\end{array}$ & $\begin{array}{l}r=0.01 \\
(p=0.93)\end{array}$ & 1.0 \\
\hline
\end{tabular}

r: Pearson correlation coefficient.

\section{Discussion}

Shared decision making is becoming dominant in gynecology. This approach has ethical and clinical benefits, ${ }^{9}$ however its implementation is challenging. One important factor in this process is patient autonomy. In this study we evaluated a questionnaire, previously used for quantifying patient au- tonomy in deciding about aesthetic procedures, ${ }^{5}$ to quantify patient autonomy in women with CPP scheduled for diagnostic laparoscopy. Our results showed that the quantification of patient autonomy can provide details about the domains of autonomy: competence, information and freedom. We were also able to identify variables that can affect these domains.

Educational level can affect many aspects of the decision process in health care. In the current study, patients were predominantly from low income population (83\%). However, there were social inequalities even among them. Fifty percent of the patients did not complete the compulsory fundamental educational level. In clinical trials the comprehension of informed consent is impaired by low educational level. ${ }^{10}$ At the time of deciding to undergo hysterectomy for treating benign gynecologic disease, the unjustified fear of cancer is more common among less educated women. ${ }^{11}$ Men from underserved communities are at higher risk of misunderstanding medical terms associated with diagnosis and treatment of prostate cancer. ${ }^{12}$ Our quantitative analysis showed that the scores for competence and information were lower among less educated women. Although limited by the study design, a cross-sectional survey, our data provided evidence that usual care might not warrant autonomy for women with low educational level. Strategies based on decision aids are needed to improve the shared decision making for those patients. $^{13}$

The presence of symptoms of depression among women with CPP is high. While the prevalence of depression is around $21 \%$ among women in general population ${ }^{14}$, among patients with gynecological pain it is up to $35 \% .^{15}$ In our study, $34.6 \%$ of patients presented symptoms of depression. In this group the score for information were significantly lower. Some studies in clinical ethics have demonstrated that depression can impair the ability to appreciate significance of information about the illness and the consequences of treatment options. ${ }^{16}$ Our data reinforce the need of screening psychiatric disorders in women with CPP. In the presence of signs of depression, the patient should be properly evaluated before the decision about invasive diagnostic procedures.

In conclusion, we were to show that systematic evaluation of patient autonomy can provide clinical relevant information in gynecology. The quantification of the domains of patient autonomy might also be important for research on factors affecting the validity of informed consent in patients with low educational level or symptoms of anxiety and depression.

\section{Acknowledgments}

Fundação de Apoio ao Ensino, Pesquisa e Assistência do Hospital das Clínicas da Faculdade de Medicina de Ribeirão Preto da Universidade de São Paulo (FAEPA).

FAEPA had no involvement in study design; in the collection, analysis and interpretation of data; in the writing of the report; and in the decision to submit the article for publication. 
Table 4 Scores for autonomy components in women with chronic pelvic pain

\begin{tabular}{|l|l|l|l|l|l|l|}
\hline Variable & Competence & $P$ & Information & $P$ & Freedom & $P$ \\
\hline Age & & 0.32 & & 0.15 & & 0.76 \\
\hline$<33$ years & $0.90(0.11)$ & & $0.92(0.03)$ & & $0.88(0.09)$ & \\
\hline$\geq 33$ years & $0.87(0.11)$ & & $0.91(0.05)$ & & $0.87(0.08)$ & \\
\hline Educational attainment & & 0.006 & & 0.02 & & 0.10 \\
\hline Incomplete elementary school & $0.85(0.13)$ & & $0.90(0.05)$ & & $0.86(0.08)$ & \\
\hline Elementary school or more & $0.92(0.07)$ & & $0.93(0.04)$ & & $0.89(0.09)$ & \\
\hline Marital status & & 0.43 & & 0.95 & & 0.84 \\
\hline Single & $0.90(0.03)$ & & $0.92(0.05)$ & & $0.87(0.1)$ & \\
\hline Married & $0.88(0.02)$ & & $0.92(0.04)$ & & $0.88(0.08)$ & \\
\hline Familial monthly income & & 0.36 & & 0.16 & & 0.96 \\
\hline$<$ US\$1,000.00 & $0.88(0.11)$ & & $0.91(0.04)$ & & $0.87(0.09)$ & \\
\hline$\geq$ US\$1,000.00 & $0.91(0.08)$ & & $0.93(0.05)$ & & $0.88(0.10)$ & \\
\hline Pain intensity & & 0.81 & & & & 0.12 \\
\hline Moderate & $0.88(0.10)$ & & $0.91(0.05)$ & & $0.85(0.09)$ & \\
\hline Severe & $0.89(0.12)$ & & $0.92(0.04)$ & & $0.89(0.08)$ & \\
\hline Pain duration & & 0.59 & & & & 0.65 \\
\hline$<2$ years & $0.89(0.12)$ & & $0.91(0.05)$ & & $0.87(0.08)$ & \\
\hline$\geq 2$ years & $0.88(0.10)$ & & $0.92(0.04)$ & & $0.88(0.09)$ & \\
\hline Anxiety & & 0.66 & & 0.05 & & 0.29 \\
\hline Yes & $0.88(0.12)$ & & $0.91(0.04)$ & & $0.86(0.08)$ & \\
\hline No & $0.89(0.12)$ & & $0.93(0.05)$ & & $0.89(0.09)$ & \\
\hline Depression & & 0.34 & & 0.01 & & 0.63 \\
\hline Yes & $0.86(0.12)$ & & $0.90(0.04)$ & & $0.87(0.08)$ & \\
\hline No & $0.89(0.11)$ & & $0.93(0.04)$ & & $0.88(0.09)$ & \\
\hline
\end{tabular}

Scores are presented as mean standard deviation (SD), P values were calculated using Student $t$-test.

\section{References}

1 Tanderup M, Reddy S, Patel T, Nielsen BB. Informed consent in medical decision-making in commercial gestational surrogacy: a mixed methods study in New Delhi, India. Acta Obstet Gynecol Scand 2015;94(5):465-472

2 Nijhawan LP, Janodia MD, Muddukrishna BS, et al. Informed consent: Issues and challenges. J Adv Pharm Technol Res 2013; 4(3):134-140

3 Beauchamp TL, Childress JF. Principles of biomedical ethics. 7th ed. New York: Oxford University Press; 2013

4 Kang SB, Chung HH, Lee HP, Lee JY, Chang YS. Impact of diagnostic laparoscopy on the management of chronic pelvic pain. Surg Endosc 2007;21(6):916-919

5 Auricchio AM, Massarollo MC. [Aesthetic procedures: client's perception regarding the information given for the decision making process]. Rev Esc Enferm USP 2007;41(1):13-20 Portuguese.

6 Jensen MP, Chen C, Brugger AM. Interpretation of visual analog scale ratings and change scores: a reanalysis of two clinical trials of postoperative pain. J Pain 2003;4(7):407-414

7 Zigmond AS, Snaith RP. The hospital anxiety and depression scale. Acta Psychiatr Scand 1983;67(6):361-370

8 Bjelland I, Dahl AA, Haug TT, Neckelmann D. The validity of the Hospital Anxiety and Depression Scale. An updated literature review. J Psychosom Res 2002;52(2):69-77
9 O'Connor AM, Bennett CL, Stacey D, et al. Decision aids for people facing health treatment or screening decisions. Cochrane Database Syst Rev 2009;(3):CD001431

10 Moodley K, Pather M, Myer L. Informed consent and participant perceptions of influenza vaccine trials in South Africa. J Med Ethics 2005;31(12):727-732

11 Gallicchio L, Harvey LA, Kjerulff KH. Fear of cancer among women undergoing hysterectomy for benign conditions. Psychosom Med 2005;67(3):420-424

12 Kilbridge KL, Fraser G, Krahn M, et al. Lack of comprehension of common prostate cancer terms in an underserved population. J Clin Oncol 2009;27(12):2015-2021

13 Stacey D, Légaré F, Col NF, et al. Decision aids for people facing health treatment or screening decisions. Cochrane Database Syst Rev 2014;1:CD001431

14 Kessler RC, McGonagle KA, Zhao S, et al. Lifetime and 12-month prevalence of DSM-III-R psychiatric disorders in the United States. Results from the National Comorbidity Survey. Arch Gen Psychiatry 1994;51(1):8-19

15 Poleshuck EL, Bair MJ, Kroenke K, Watts A, Tu X, Giles DE. Pain and depression in gynecology patients. Psychosomatics 2009;50(3): 270-276

16 Hindmarch T, Hotopf M, Owen GS. Depression and decisionmaking capacity for treatment or research: a systematic review. BMC Med Ethics 2013;14:54 